\title{
Theoretical and methodological foundations for the study of federalism
}

\author{
Vladimir Mikhailovich Platonov ${ }^{1}$ \\ RUDN University, Faculty of Humanities and Social Sciences, Department of Political Analysis and \\ Management, Moscow, Russia
}

\begin{abstract}
The purpose of the research is to determine the basic methodological rules that allow to form a science-based concept of separation of powers between the levels of government, taking into account the cultural and historical conditions of development of Russian society, the establishment in it of stable principles of relations in the public sphere, standards and stereotypes of social interaction. The research conducted on the basis of the dialectical method, which was used in combination with the systematic method, the historical method and the socio-cultural vision of political and legal phenomena, showed the following results: a) there are only general guidelines that guide states in choosing a federal model, not any of its benchmarks; b) the problem of correlation of vertical separation of powers with responsibility and cultural and historical specificity in the implementation of powers in the sphere of joint jurisdiction of the federal center and the subjects of the federation is the key one; c) significant in the methodology of the study of federalism is the assessment of the weakness of political ambitions of the power elites in relation to the role of socio-economic factors that determine the degree of effectiveness of the implementation of their powers by the subjects of public authority; d) the separation of powers in a federal state is a dynamic process, the content and direction of which are conditioned by concrete and historical tasks; e) the centralization of federal relations in Russia is a factor in their evolution and dynamics. The novelty of the research is due to the author's approach to the substantiation of the system of methodological rules, which will ensure a) the integrity of the state, b) the need for decentralization of power on the basis of the principles of federalism, c) the definition of the principles that determine the model of separation of powers.
\end{abstract}

Keywords: federalism, political culture, legal culture, subjects, cultural and historical preconditions

\section{Introduction}

The prerequisites of the research are caused by the task of strengthening statehood, achieving a balance of interests in the relationship between Russia and its subjects, the formation of an adequate model of delimitation of competencies and powers between them. It should be taken into account that the delimitation of powers is a potentially conflict area

\footnotetext{
${ }^{1}$ Corresponding author: platonov-vm@,rudn.ru
} 
[1-3]. Consequently, determining the principles, order, and content of their delimitation is a necessary condition for ensuring the stability of the Russian model of the federal state structure.

Federal relations are a potentially conflictual area. Determining their principles, order, and content is a necessary condition for the sustainability of statehood. Models and effective mechanisms of separation of powers and jurisdictions between federal and regional bodies of state power in Russia have as their basis the cultural and historical paradigm of development of the federal state system of Russia. Research Hypothesis is expressed in the fact that the principles, models and effective mechanisms of delimitation of powers and competencies between the federal and regional bodies of state power in the Russian Federation have as their basis the cultural and historical paradigm of development of the federal state system of Russia in the Soviet and post-Soviet periods [4-6].

Important in this regard is to determine the basic methodological rules that allow to form a science-based concept of separation of powers between the levels of government, taking into account the cultural and historical conditions of development of Russian society, the rooting in it of sustainable principles of relations with the public authorities, standards and stereotypes of social interaction. This is the purpose of this research. Objectives of the research are to substantiate such a system of methodological rules, which will ensure a) the integrity of the Russian state, b) the real need for decentralization of power based on the principles of federalism, c) a meaningful definition of the principles that determine the model of delimitation of powers between the federal center and the subjects of the federation (Will it be a competition of powers, should they be mutually complementary? Should the national factor be taken into account in the division of powers, and if so, to what extent, and in what combination with economic factors?).

\section{Methods}

The dialectical method used in the study allowed us to evaluate the problem of delimitation of competencies and powers through the prism of interrelation and interdependence of social phenomena. In combination with the systematic method, the historical method and the socio-cultural vision of political and legal phenomena, the dialectical method led to the conclusion about the "embeddedness" of federal relations in the political and legal culture of society. The consequence was an analysis of the research problem through the prism of the cultural and historical specifics of the development of Russian society and the state. The results of the research are also based on inductive and deductive inferences combined with analysis and synthesis as general scientific research methods.

The research also used the following methods: comparative-legal (to compare the political and legal institutions and procedures in which the separation of powers is expressed in Russia and in foreign countries), formal-legal (to determine the legal concepts and categories related to the object and subject of the study), structural-functional method (which allowed to compare the role and importance of individual elements of political and legal culture to address the objectives of the research).

\section{$3 \quad$ Results}

The problem of correlation of vertical separation of powers with responsibility and cultural-historical specificity acquires the greatest importance in the sphere of joint jurisdiction of the federal center and the subjects of the federation. The situation here is complicated by the internal contradiction of this sphere of federal competence. The 
separation of powers is inextricably linked to the objective need to coordinate the efforts of different levels of government and their interaction, with the need to reconcile the interests of the federal center and those of the regions. It is here that the weakness of the political ambitions of the power elites becomes apparent, in correlation with the enormous importance of socio-economic factors that determine the degree of effectiveness of the implementation of their powers by the subjects of public authority and, consequently, the amount of power that they are objectively able to "digest" [7].

The separation of powers in a federal state is a dynamic process, the content and direction of which are conditioned by the concrete and historical tasks facing the state at each historical moment of its existence [8]. The essence of this process remains relatively unchanged, due to the cultural and historical paradigm of the development of the federal state system.

A concrete-historical approach to the problems of Russian federalism faces the need to find the roots of political, legal and socio-economic disintegration, which poses a threat to Russian statehood. The factors of such disintegration have a complex content. Consequently, the federal structure of the Russian state must take into account not only the desire for political self-expression of the power elites, but also the objective patterns of socio-economic and cultural development. In particular, it should be taken into account that the amount of authority granted to particular levels of government in a federal state is conditioned by the degree of sufficiency of resources available to the relevant level of government, as well as the readiness of the government to effectively dispose of these resources. Here it is methodologically important to determine indicators that reflect the degree of readiness of the subject of the Russian Federation to implement the political powers that the federal center is ready to grant it in accordance with the constitutional principles of their division.

The centralization of federal relations in Russia is a factor in their evolution, dynamics. In this connection, it is methodologically important to determine up to what point centralization does not lead to excessive concentration of power in the hands of the federal center, what mechanisms exist or can be created to prevent such excessive concentration. The starting point in the conceptual justification of the principles of delineation of authority between the levels of government in the Russian Federation may be the idea that its criterion should be the ability of one or another level of government to effectively use resources and solve socio-economic and political problems within the existing constitutional legal framework.

\section{Discussion}

The results of the study organically fit into existing scientific concepts of federalism and their corresponding points of view. The methodology of the study of federalism has at its core the multiplicity of its interpretations. One of them is the understanding of it as a phenomenon conditioned by the peculiarities of the political and legal culture of society and the trends in its cultural and historical development that characterize it. The understanding of the essence of federalism in Western political and legal cultures includes the following methodological features:

1. The problem of the correlation between public power and social structures comes to the fore, rather than the question of the interaction of the structural units of the state mechanism; 
2. As a consequence, the idea of delimitation of competencies and powers between subjects of state power is replaced by the issue of distribution of powers between the state and various social structures;

3. Federalism appears as a special concept of social interaction, not just the territorial organization of power;

4. Such social interaction presupposes a plurality of centers of power, the development of self-government, a variety of political interests, and corresponding organizational-institutional structures. These components methodologically make up the concept of federalism as a whole.

This understanding of federalism is based on stereotypes of political and legal thinking that are products of the liberal-democratic structure of Western society. As a consequence, it is not quite compatible with the specificity of typologically different societies. Common features in the concepts of federalism can be found in its ability to resolve conflicts, the nature of which, however, may differ significantly depending on the historical and cultural specifics of the development of particular federal states ranging from the struggle for the volume of public authority between different levels of government to the confrontation between civil society and the state.

The differences between the cultural and historical images of federalism manifest themselves in the following: a) the purposes of use; b) the dominants that predetermine the nature and content of the system of distribution of competencies and powers between the different levels of government; c) the degree of influence of social and economic factors on federal relations; d) the characteristics of political and legal culture; e) the dynamics of the struggle between centralization and decentralization elements that characterize the organization of state power [9].

Researchers note that centralization is the dominant trend in modern federations [10, 11]. It is a reaction to separatism, socio-economic problems, and the inability of regional authorities to provide intensive economic development of their territories.

Under such conditions, the subjects of the federation are relatively weak, and the federation seeks to suppress any attempts by them to claim any sovereign rights. In this context, Western federal states in a sense sacralize the principles of "legal unity", fidelity to the federation, solidarity and subsidiarity [12], ensuring the integrity of the state in the construction of federalism. These ideas are quite compatible with the political and legal culture of modern Russia, and some of them are actively used in Russian constitutional law and constitutional practice. The understanding of the essence of federalism in Russian political and legal cultures includes the following methodological features:

1. The impetus for the development of the system of interaction between the federal center and the subjects of the federation is not a conflict of interests between them or the confrontation between the state and civil society. Considerations of a socio-economic nature come to the fore.

2. The purpose of federal power in Russia is not to satisfy the claims of the subjects of the federation to a certain volume of authority, but to ensure the involvement of regional authorities in the process of solving problems of national importance, their awareness of the commonality and complementarity of federal and regional interests.

3. This approach prevents the strengthening of regional political elites and ensures that their interests are subordinated to public needs, while preserving and supporting the cultural and socio-economic specificities of the regions.

\section{Conclusion}


Modern constitutionalists have repeatedly noted that there are no identical or perfect models of government in the world [13-15]. There are only general guidelines that guide states in choosing a federal model. First and foremost, it is the need for just such a form of government to achieve social compromise, the integrity of the country. As the world experience of the federal organization of the state shows, relatively successful are those of them, where the issue of vertical division of powers is solved in close connection with ensuring the responsibility of different levels of government for the implemented public powers and taking into account the specific historical and cultural specifics of society and the state.

The methodology of the study of Russian federalism is characterized by significant differences from the principles of the study of this phenomenon in its Western understanding. The key difference lies in the specific composition of the subjects, through the interaction of which the features of federalism are revealed, as well as in different assessments of the degree of significance of the conflicting nature of their interaction ranging from absolutization of the role of antagonisms between society and the state to the idea of complementarity and interdependence of different levels of public authority combined with an awareness of their common tasks [16].

\section{References}

1. S. Dullin, E. Forestier-Peyrat, Journal of the History of International Law, 19 (2017)

2. B.C. Harzl, International Journal of Foresight and Innovation Policy, 14(1) (2019)

3. T. Lundstedt, Nordic Journal of International Law, 89 (2020). https://doi: 10/1163/15718107-BJA10002

4. Z. Kembayev, Review of Central and East European Law, 43 (2018). https://doi: 10.1163/15730352-04304003

5. W. Sunderland, Modern History of Russia, 1 (2017). https://doi: 10.21638/11701/spbu24.2017.110

6. D.D. Laitin, Annual Review of Political Science, 3 (2000)

7. G. Yusupova, Nationalities Papers, 44(1) (2016). https://doi: 10.1080/00905992.2015.1061983

8. A. Benz, C. Colino, Regional and Federal Studies, 21, 4-5 (2011). https://doi: 10.1080/13597566.2011.578886

9. A.D. Gulyakov, Journal of Siberian Federal University, Humanities and Social Sciences, 13(10) (2020). https://doi: 10.17516/1997-1370-0675

10. I. Zulkarnay, Public Administration Issues, 5, 116-132 (2018). https://doi: 10.17323/1999-5431-2018-0-5-116-132

11. A. Konitzer, S.K. Wegren, The Journal of Federalism, 36(4) 2006. https://doi: 10.1093/publius/pj1004

12. J. Drew, B. Grant, The Journal of Federalism, 47(4) (2017). https://doi: 10/1093/publius/pjx039

13. J. McGarry, Nations and Nationalism, 24(3) (2018). https://doi: 10.1111/nana.12447

14. K. Matsuzato, Europe-Asia Studies, 69(7) (2017). https://doi: 10.1080/09668136.2017.1374056

15. A. Stepan, Post-Soviet Affairs, 16(2) (2000). https://doi: 10.1080/1060586X.2000.10641484 
16. H. Küpper, Review of Central and East European Law, 38 (2013). https://doi: 10.1163/15730352-00000003 